AVELINO, Victor Pereira; BARBOSA, Ycarim Melgaço. Entraves à implementação da política de enfrentamento à violência contra mulheres: um problema de governança pública. Oikos: Família e Sociedade em Debate, v. 31, n. 1, p.57-75, 2020 http://dx.doi.org/10.31423/oikos.v31i1.9933

\title{
ENTRAVES À IMPLEMENTACÃO DA POLÍTICA DE ENFRENTAMENTO À VIOLÊNCIA CONTRA MULHERES: UM PROBLEMA DE GOVERNANÇA PÚBLICA
}

\section{BARRIERS TO THE IMPLEMENTATION OF THE POLICY TO FIGHT VIOLENCE AGAINST WOMEN: A PUBLIC GOVERNANCE PROBLEM}

\section{BARRERAS A LA APLICACIÓN DE LA POLÍTICA PARA COMBATIR LA VIOLENCIA CONTRA LAS MUJERES: UN PROBLEMA DE GOBERNANZA PÚBLICA}

\section{Resumo}

Victor Pereira Avelino ${ }^{1}$ Ycarim Melgaço Barbosa ${ }^{2}$

O artigo discute o processo de implementação de políticas públicas de enfrentamento à violência contra mulheres a partir da perspectiva da burocracia de nível de rua representada por policiais civis e militares. A pesquisa documental se deu a partir de boletins de ocorrência de violência doméstica contra mulher, registrados em 2019 pelas Polícias Civil e Militar do Estado de Goiás. A inexistência de um patamar mínimo de governança pública gera problema de agência em que policiais civis e militares, descumprindo o que determina a Lei 11.340/2006, definem de forma discricionária os casos que receberão a atenção estatal, resultando na não apuração de mais de $52 \%$ dos crimes noticiados no universo pesquisado. Assim, o programa normativo de enfrentamento à violência contra mulheres se depara com o desafio de coordenação entre diversos setores e níveis de Governo e de governança em órgãos e entidades da administração pública, que geram entraves à sua implementação.

Palavras-chave: Violência doméstica. Políticas públicas. Implementação.

\section{Abstract}

The article discusses the process of implementing public policies to combat violence against women from the perspective of street-level bureaucracy represented by civilian and military police. The documentary research was based on bulletins of the occurrence of domestic violence against women, registered in 2019 by the Civil and Military Police of the State of Goiás. The lack of a minimum level of public governance creates an agency problem in which civil and military police officers, disregarding the provisions of Law 11.340 / 2006, they define in a discretionary manner the cases that will receive state attention, resulting in the failure to investigate more than $52 \%$ of the crimes reported in the surveyed universe. Thus, the normative program to confront violence against women faces the challenge of coordination between different sectors and levels of Government and governance in public administration bodies and entities, which create obstacles to its implementation.

Keywords: Domestic violence. Public policy. Implementation.

\section{Resumen}

El artículo analiza el proceso de implementación de políticas públicas para combatir la violencia contra las mujeres desde la perspectiva de la burocracia callejera representada por la policía civil y militar. La investigación documental se basó en informes de la violencia doméstica contra las mujeres, registrada en 2019 por la Policía Civil y Militar del Estado de Goiás. La falta de un nivel mínimo de gobernanza pública crea un problema de agencia en el que los agentes de la policía civil y militar, sin tener en cuenta las disposiciones de la Ley 11.340 / 2006, definen de manera discrecional los casos que recibirán atención estatal, lo que resulta en la falta de investigación de más del $52 \%$ de los delitos denunciados en el universo encuestado. Por lo tanto, el programa normativo para enfrentar la violencia contra las mujeres enfrenta el desafío de la coordinación entre los diferentes sectores y niveles de gobierno y gobierno en los organismos y entidades de la administración pública, lo que crea obstáculos para su implementación.

Palabras-clave: Violencia doméstica. Políticas publicas. Implementación.

\footnotetext{
${ }^{1}$ Graduação em Direito (Universidade Federal de Goiás (UFG). Pós-graduação em Criminologia (UFG) e em Análise Criminal (Instituto de Pós-Graduação -IPOG). Mestrando em Desenvolvimento e Planejamento Territorial (PUC Goiás). Delegado de Polícia Civil do Estado de Goiás. E-mail: victoravelino86@gmail.com

${ }^{2}$ Graduação em Direito pela Universidade Federal de Goiás (UFG). Doutorado em Geografia (USP), Pós-doutorado em Economia (IE-UNICAMP) e em Administração de Empresas (FEARP-USP). Coordenador do NUPECAMCambury. Professor na Pontifícia Universidade Católica de Goiás. E-mail: ycarim@gmail.com
} 


\section{INTRODUÇÃO}

Os movimentos feministas, não obstante a diversidade de suas teorias, apresentam como característica comum a crítica à dualidade entre as esferas pública e privada, em que aquela se baseia em princípios universais e na razão, e esta abrange as relações pessoais e os afetos, distinção essa que resulta de um processo histórico e político que produz papéis, comportamentos e limites baseados nas identidades de gênero (BIROLI, 2018). Esses estereótipos criados atribuíram às mulheres papéis voltados à vida doméstica, tais como atividades de cuidado com filhos, esposos, membros mais velhos, dependentes e enfermos, excluindo-as da esfera pública. A privacidade da vida doméstica passaria então pela não interferência do Estado nas relações interpessoais travadas nesse âmbito, o que representou, em grande medida, a preservação da desigualdade de poder entre os integrantes da família e foi utilizada como ferramenta de manutenção da dominação masculina.

Não obstante a transformação das relações matrimoniais e familiares contemporâneas, os processos de inserção maciça de mulheres no mercado de trabalho e de conscientização feminina, ainda se observa a maior vulnerabilidade das mulheres na esfera privada, vulnerabilidade essa que atinge seu ponto mais alto nas ofensas ao direito fundamental à integridade física. Em 2017 e 2018, respectivamente, ocorreram, no Brasil, 4.540 (quatro mil quinhentos e quarenta) e 4.069 (quatro mil e sessenta e nove) homicídios de mulheres. Dessas mortes, 1.151 (mil cento e cinquenta e uma), em 2017, e 1.206 (mil duzentas e seis), em 2018, ocorreram por razões da condição do sexo feminino, configurando assim o delito de feminicídio. No mesmo período analisado, foram registrados em todo o país 252.895 (duzentos e cinquenta e dois mil oitocentos e noventa e cinco) e 263.067 (duzentos e sessenta e três mil e sessenta e sete) casos de violência doméstica (FBSP, 2019).

O questionamento à privacidade no âmbito familiar surgiu como forma de expor as agressões sofridas por crianças e mulheres no espaço doméstico, situação essa que demanda a atuação estatal e regulação protetora, já que, para meninas e mulheres, a residência familiar está longe de ser um espaço de privacidade e proteção (BIROLI, 2018).

O Estado brasileiro somente se posicionou frente à violência contra mulheres por meio de um programa normativo multifocal e abrangente com a criação da Secretaria Especial de Políticas para Mulheres (SPM), em 2003, e a promulgação dos Planos Nacionais de Políticas para Mulheres, a partir de 2005. Essa tomada de posição se insere em um contexto mundial de mudanças culturais e sociais, que impuseram aos governos a necessidade de modificação de 
suas agendas políticas, que passaram a se debruçar sobre problemas públicos complexos que abordam questões e valores emergentes, como gênero, direitos humanos, raça, meio ambiente, entre outros.

O presente trabalho se propõe analisar a implementação de políticas públicas de enfrentamento à violência contra mulheres a partir de um ponto específico, qual seja, a atuação dos policiais militares e civis responsáveis pela prestação direta do serviço público de policiamento, primordial para o enfrentamento à violência doméstica. Nesse contexto específico da implementação do referido programa estatal, buscar-se-á demonstrar que a falta de um patamar mínimo de governança pública nos órgãos de segurança pública estaduais permite que os agentes de linha abusem da discricionariedade inerente ao trabalho policial, criando assim um problema de agência em que policiais civis e militares promovem a filtragem dos casos de violência doméstica que receberão a atenção da justiça criminal. Serão ainda investigados os motivos informados pelos burocratas de nível de rua para atuarem em desconformidade com o previsto no programa de enfrentamento à violência contra mulheres, bem como possíveis demonstrações de preconceito e machismo nas versões por eles apresentadas.

Para tanto, o artigo se divide em quatro partes, incluída a presente introdução. Em primeiro lugar, apresentar-se-á o referencial teórico que norteou a análise dos casos estudados, com ênfase na evolução das políticas públicas de enfrentamento à violência contra mulheres no Brasil e na importância da chamada "burocracia de nível de rua". Em seguida, será especificada a metodologia utilizada para a seleção dos casos e para a análise dos dados coletados por meio de pesquisa documental que teve como fonte primária os 2.059 (dois mil e cinquenta e nove) boletins de ocorrência de violência doméstica contra mulher registrados no ano de 2019 nos 29 (vinte e nove) municípios goianos que compõem a Região Integrada de Desenvolvimento do Distrito Federal e Entorno (RIDE/DF). Por fim, a partir dos resultados obtidos, serão apresentadas as principais conclusões acerca da atuação de policiais civis e militares na implementação do programa normativo, demonstrando que a governança pública se coloca como importante ferramenta no enfrentamento aos problemas de agência identificados. 


\section{A VIOLÊNCIA CONTRA MULHERES COMO PROBLEMA PÚBLICO: A FORMAÇÃO DA AGENDA POLÍTICA NO BRASIL}

Segundo Secchi (2017, p. 44), "um problema é a discrepância entre o status quo e uma situação ideal possível. Um problema público é a diferença entre o que é e aquilo que se gostaria que fosse a realidade pública". Interessa à análise de políticas públicas entender como uma questão específica se torna importante e passa a chamar a atenção do Governo e a integrar sua agenda. Em seu modelo de Múltiplos Fluxos (Multiple Streams Model), John Kingdon propõe a existência de três fluxos decisórios, que se comportam de forma relativamente independente, mas que, ao convergirem, são capazes de promover a mudança da agenda governamental. No primeiro fluxo, o autor analisa a forma como, em meio a uma infinidade de questões, algumas se transformam em problemas ao chamar a atenção dos formuladores de políticas. Tal processo de seleção seria influenciado por três mecanismos básicos: indicadores; eventos, crises e símbolos; e feedback das ações governamentais. No segundo fluxo, são consideradas as alternativas e soluções criadas que se aplicariam ao problema e, por fim, o fluxo político, que aborda a atuação de grupos de pressão, de movimentos sociais e da opinião pública sobre o clima social necessário para mudanças políticas (CAPELLA, 2006).

As pressões dos movimentos feministas, a divulgação midiática de casos de violência contra mulheres, bem como o clima social vivenciado no país durante o processo de redemocratização iniciado em 1979, foram responsáveis pela abertura da janela de mudança da agenda governamental que resultou na criação, em agosto de 1985, durante o Governo de Franco Montoro no Estado de São Paulo, da primeira Delegacia de Polícia de Defesa da Mulher (DDM) do Brasil e da América Latina. O projeto em questão, proposto pelo então Secretário Estadual de Segurança Pública, Michel Temer, estabelecia que a DDM contaria com policiais civis do sexo feminino, pois partia do princípio de que as policiais civis seriam mais solidárias com as ocorrências apresentadas por mulheres. Com base na experiência em São Paulo, Delegacias de Defesa da Mulher, posteriormente identificadas como Delegacias Especializadas no Atendimento às Mulheres (DEAMs), foram criadas em todos os estados brasileiros e se tornaram o principal aparelho público de alcance nacional no combate à violência contra mulheres (SANTOS, 2010).

A escassez e a precariedade da infraestrutura social de atendimento às mulheres em situação de violência, concentrada no atendimento por meio de poucas delegacias especializadas e no encaminhamento a casas-abrigo; as críticas à premissa de que as policiais 
civis prestariam melhor atendimento a mulheres vítimas de violência, surgidas em razão da observação das mesmas práticas negligentes perpetradas em unidades policiais compostas por homens; e a ausência de um programa nacional de enfrentamento à violência contra mulheres faz com que a atuação governamental no período de 1985 a 2002 não seja considerada uma efetiva política pública (IPEA, 2010).

Essa situação começa a mudar a partir dos anos 2000, quando o Brasil passou a sofrer maior pressão internacional para combater a violência contra mulheres, surgindo uma nova janela de oportunidade a partir da maior articulação entre os movimentos feministas e o Estado, culminando com a criação da Secretaria Especial de Políticas para as Mulheres pelo Governo Federal, no ano de 2003, e com a realização de conferências nacionais, cujas diretrizes levaram à formulação dos Planos Nacionais de Políticas para as Mulheres. A complexidade e a abrangência do problema da violência contra mulheres exigiram do Governo brasileiro alterações significativas na formulação e implementação de suas políticas públicas, motivo pelo qual os Planos Nacionais de Política para Mulheres buscaram instituir a integração entre diversas agências públicas, níveis governamentais e setores sociais para que a atuação estatal ocorresse de forma satisfatória. No período entre 2005 e 2015, foram elaborados pelo Governo Federal três Planos Nacionais de Políticas para Mulheres, os quais elencaram o enfrentamento à violência como um dos principais eixos de atuação para garantir às mulheres uma vida mais digna. Foram traçadas diversas metas, tais como a implementação e o fortalecimento da política nacional de enfrentamento; a garantia de atendimento integral, humanizado e de qualidade às mulheres em situação de violência doméstica; a redução dos índices criminais; a transversalidade das temáticas de gênero e violência contra mulheres nas mais diversas políticas públicas setoriais; a intersetorialidade entre órgãos e atores de diferentes níveis de governo (BRASIL, 2005; BRASIL, 2008; BRASIL, 2011).

Visando atribuir embasamento jurídico a toda a política de enfrentamento à violência contra mulheres, foi promulgada, em 7 de agosto de 2006, a Lei $n . \stackrel{0}{11.340 / 2006}$, que recebeu a alcunha de Lei Maria da Penha como meio simbólico de reparação à morosidade do sistema de justiça brasileiro em julgar o caso de Maria da Penha Maia Fernandes. O referido dispositivo legal representa, ainda que do ponto de vista formal, o abandono, pelo Estado brasileiro, da posição de neutralidade frente ao problema público da violência contra mulheres, reconhecendo sua responsabilidade na superação da desigualdade de gênero (BRASIL, 2006).

Corroborando os princípios fundamentais propostos pelos Planos Nacionais de Políticas para Mulheres, a Lei Maria da Penha prevê um tratamento multidisciplinar à violência de gênero, pois, além de reforçar a criminalização da violência contra mulheres e apresentar 
mecanismos capazes de aperfeiçoar a prestação jurisdicional, apresenta medidas protetivas e preventivas, que visam o acolhimento emergencial das vítimas, seu isolamento do agressor e a prestação de assistencial social (CERQUEIRA et al., 2015).

Em seu artigo 7ํㅡㄹ a referida lei, baseada na Declaração sobre a Eliminação da Violência Contra a Mulher, define as formas de violência doméstica e familiar contra a mulher, abrangendo não apenas as de ordem física e sexual, já previstas pelo ordenamento jurídico penal brasileiro, mas também psicológica, capaz de causar dano emocional e diminuição da autoestima da mulher; patrimonial, que representa a retenção, subtração ou destruição de objetos; e moral, quando são perpetradas condutas que configurem calúnia, difamação ou injúria (BRASIL, 2006).

Em seu artigo 41, a Lei $n .^{\circ} 11.340 / 2006$ estabelece a não aplicação da Lei $n .^{\circ}$ 9.099/1995 (Lei dos Juizados Especiais Criminais) aos casos de lesão corporal praticada com violência doméstica e familiar contra a mulher, buscando combater a banalização dessa espécie de crime. Essa foi, de acordo com Calazans e Cortes (2011), a principal exigência dos movimentos feministas que participaram das discussões que deram origem à Lei $\mathrm{n} .^{\circ}$ 11.340/2006. Referida mudança processual gerou bastante divergência jurisprudencial, a ponto de a constitucionalidade do referido artigo ter sido discutida na Ação Direta de Inconstitucionalidade (ADI) n. 4.424/DF e na Ação Declaratória de Constitucionalidade (ADC) n..$^{19 / D F}$, ambas de 09 de fevereiro de 2012, cujo relator foi o Ministro Marco Aurélio de Melo. Após calorosos debates, os Ministros do Supremo Tribunal Federal decidiram, por maioria, assentar a natureza incondicionada da ação penal em caso de crime de lesão corporal, pouco importando a extensão dessa, praticado contra a mulher no ambiente doméstico. Dessa forma, acionadas as polícias civis e militares, seja pela própria vítima, seja por parentes ou vizinhos, e constatada, por meio de exame de corpo de delito, a lesão corporal provocada pelo agressor, este será preso em flagrante delito e conduzido a uma Delegacia de Polícia para lavratura do auto de prisão em flagrante, ainda que a vítima não deseje a atuação do Estado.

A atuação compulsória dos órgãos de segurança pública, quando notificados de casos de violência doméstica contra mulheres, visa aumentar o custo esperado da punição, aumentando a probabilidade de condenação. Busca-se, com isso, diminuir a prática criminosa.

\section{Burocratas de nível de rua, problemas de agência e governança pública}

O campo científico da análise de políticas públicas surge e se desenvolve a partir do final dos anos 1960, concebendo a ação do Estado como uma ação racional baseada em 
passos lógicos, que se inicia com a definição do problema, segue com o levantamento de alternativas e finaliza com a escolha e a implementação de uma delas (FARAH, 2018). Esse paradigma da racionalidade passa a sofrer questionamentos, dentre os quais a dúvida sobre a centralidade do processo de formulação, surgindo modelos de análise do tipo bottom-up, cujas análises focam os atores envolvidos na prestação de serviços locais (PEREZ, 2007).

Nos idos de 1980, Lipsky (2010) debruçou-se sobre as "burocracias de nível de rua", compostas por indivíduos que, além de atuarem na prestação direta dos serviços públicos, caracterizam-se pela discricionariedade substancial na execução de suas funções, pois, a todo momento, lidam com situações não antecipadas e tomam decisões críticas no nível operacional (BRONZO; COSTA, 2012).

A importância do estudo dessas interações sociais reside no fato de as políticas públicas serem permeadas por conflitos e decisões vagas, bem como pela ausência de diretrizes e guias práticos de atuação, o que cria espaço para que o agente implementador decida como colocar em prática a ação esperada, como distribuir benefícios e sanções e como estruturar a interação do cliente com o aparelho estatal. Nesse contexto, o burocrata de nível de rua acaba por inserir, na prestação do serviço público, valores, preconceitos e referências individuais relacionados com temas como raça, cor, gênero etc. (LOTTA, 2012).

Os operadores de linha reconhecem a existência de regras que regem procedimentos que devem ser por eles adotados, bem como são inteirados dos princípios e objetivos traçados pelas políticas públicas. No entanto, mesmo as políticas oficiais moldando padrões de decisões e de comportamento, os burocratas de nível de rua conseguem adaptar as práticas exigidas à realidade por eles experimentada (LOTTA, 2012). Isso porque, segundo Lispky (2010), as tarefas realizadas são complexas a ponto de normas e instruções criadas não se aplicarem a todas as alternativas que se apresentam no dia a dia do serviço, além de as situações com as quais os agentes da linha de frente têm que lidar normalmente exigirem resposta à dimensão humana do problema. Ainda segundo Lispky (2010, p. 16), "enquanto as tarefas permanecerem complexas e a intervenção humana for considerada necessária para a efetividade do serviço, a discricionariedade continuará característica de muitos serviços públicos”.

A complexidade da implementação de serviços públicos está diretamente relacionada com o fato de a sociedade buscar, ao mesmo tempo, imparcialidade de suas agências públicas e compaixão e flexibilidade por circunstâncias especiais. Como esclarece Lotta (2012, p. 25):

As pessoas chegam aos burocratas de rua como indivíduos únicos, portadores de diferentes experiências de vida, personalidades, expectativas e necessidades. No entanto, quando encontram com os burocratas de rua, que são a personificação do Estado, transformam-se em clientes, identificáveis e alocáveis em alguns padrões e 
categorias sociais. Passam a ser tratados, portanto, de acordo com esses padrões unificados e indiferenciados. Os clientes tendem a experimentar suas necessidades como problemas individuais e suas demandas como expressões individuais de uma expectativa, esperando, portanto, tratamentos individuais para aquelas questões. Já os burocratas de rua experimentam os problemas dos clientes como categorias de ação e suas demandas individuais como solicitações agregadas, padronizadas e categorizadas dentro das possibilidades de respostas e serviços que estão aptos a prestar.

Lipsky (2010) conclui que as decisões dos burocratas de nível de rua, as rotinas que estabelecem e os dispositivos que criam para lidar com as incertezas e as pressões do trabalho moldam o comportamento da agência que representam e, consequentemente, as políticas públicas entregues pelo Estado. Ocorre que essa realidade configura um problema na relação principal e agente, definida por Jensen e Meckling (1976) como um contrato em que uma ou mais pessoas - o principal - contratam outra pessoa - o agente - para desempenhar alguma tarefa em seu favor, tarefa essa que envolve a delegação da tomada de decisão ao agente.

A prestação de serviços públicos por parte do Estado envolve a delegação de poder e, tendo em vista a impossibilidade de formular leis que disciplinem todas as situações da vida real, os burocratas conservam um espaço de autonomia considerável. No entanto, os seus objetivos não têm, e normalmente não são, idênticos aos dos eleitores ou dos políticos eleitos que os representam (PRZEWORSKI, 1998). Essa situação torna-se ainda mais complicada em razão da assimetria informativa, já que o agente possui vantagens de informação em relação ao principal, que pode conduzir ao risco moral, que vem a ser "a possibilidade de o agente ludibriar o principal, por exemplo, um fiscal ambiental que aceita suborno e não cumpre seu papel de aplicar multas" (SECCHI, 2017, p. 118).

Ao tratar da governança corporativa, Marques (2007) a define como um conjunto de regras que visam minimizar os problemas de agência. Como visto, os conflitos entre principal e agente também podem ser observados nas relações que envolvem o Estado e os cidadãos.

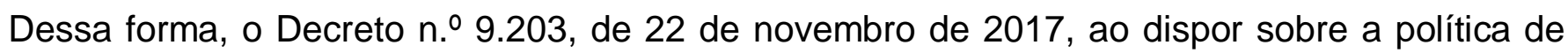
governança da administração pública federal direta, autárquica e fundacional, define governança pública como "conjunto de mecanismos de liderança, estratégia e controle postos em prática para avaliar, direcionar e monitorar a gestão, com vistas à condução de políticas públicas e à prestação de serviços de interesse da sociedade” (BRASIL, 2017, s. p.). O referido dispositivo legal estabelece como princípios da governança pública a serem aplicados pelos órgãos estatais a capacidade de resposta, a integridade, a confiabilidade, a melhoria regulatória, a prestação de contas e responsabilidade e a transparência (BRASIL, 2017). 
Dentre os referidos princípios, destaca-se, para os objetivos deste estudo, a prestação de contas e a responsabilidade (no inglês, accountability), que representa a vinculação necessária entre decisões, condutas e competências e seus respectivos responsáveis (BRASIL, 2018). A supervisão e a avaliação da atuação da burocracia envolvida na implementação de políticas públicas proporcionam uma melhor orientação dos agentes para os objetivos públicos, permitindo assim o ajuste do sistema quando da percepção de problemas. Com relação às políticas públicas de enfrentamento à violência contra mulheres, conforme se demonstrará, a ausência de mecanismos internos de controle da atuação de policiais civis e militares; a atuação inexpressiva de fiscalização por parte dos demais órgãos do sistema de justiça criminal, Ministério Público e Poder Judiciário; e a falta de um patamar mínimo de governança pública permitem que a atuação discricionária dos agentes de linha promova a filtragem dos casos de violência que receberão a atuação estatal, surgindo portanto, entraves à implementação do programa normativo.

\section{ANÁLISE DOS CASOS}

A fim de identificar o problema de agência que surge a partir do abuso da discricionariedade por parte de policiais civis e militares, o presente trabalho promoveu pesquisa documental utilizando como fonte primária os 2.059 (dois mil e cinquenta e nove) boletins de ocorrência de violência doméstica registrados no ano de 2019 nos 29 (vinte e nove) municípios goianos que compõem a Região Integrada de Desenvolvimento do Distrito Federal e Entorno (RIDE/DF). As cidades abrangidas pela pesquisa foram: Abadiânia, Água Fria de Goiás, Águas Lindas de Goiás, Alexânia, Alto Paraíso de Goiás, Alvorada do Norte, Barro Alto, Cabeceiras, Cavalcante, Cidade Ocidental, Cocalzinho de Goiás, Corumbá de Goiás, Cristalina, Flores de Goiás, Formosa, Goianésia, Luziânia, Mimoso de Goiás, Niquelândia, Novo Gama, Padre Bernardo, Pirenópolis, Planaltina, Santo Antônio do Descoberto, São João da Aliança, Simolândia, Valparaíso de Goiás, Vila Boa e Vila Propício. O Estado de Goiás instituiu, a partir de abril de 2016, o sistema Registro de Atendimento Integrado (R.A.I), que reúne, em uma única base de dados, todas as ocorrências, criminais ou não, registradas por órgãos de segurança pública, diminuindo assim a quantidade de registros duplicados e tornando mais eficiente a produção de dados criminais. No referido sistema, policiais militares, bombeiros militares e policiais civis podem documentar, em campo específico para cada aparelho público, informações acerca da ocorrência por eles atendida. Nesses históricos dos boletins de ocorrência é possível observar as impressões, os preconceitos e as justificativas 
dos agentes de linha de frente, bem como os métodos por eles utilizados ao tomarem decisões acerca das situações que se apresentam, representando, portanto, uma importante fonte de pesquisa.

Figura 1 - Municípios que compõem a RIDEIDF

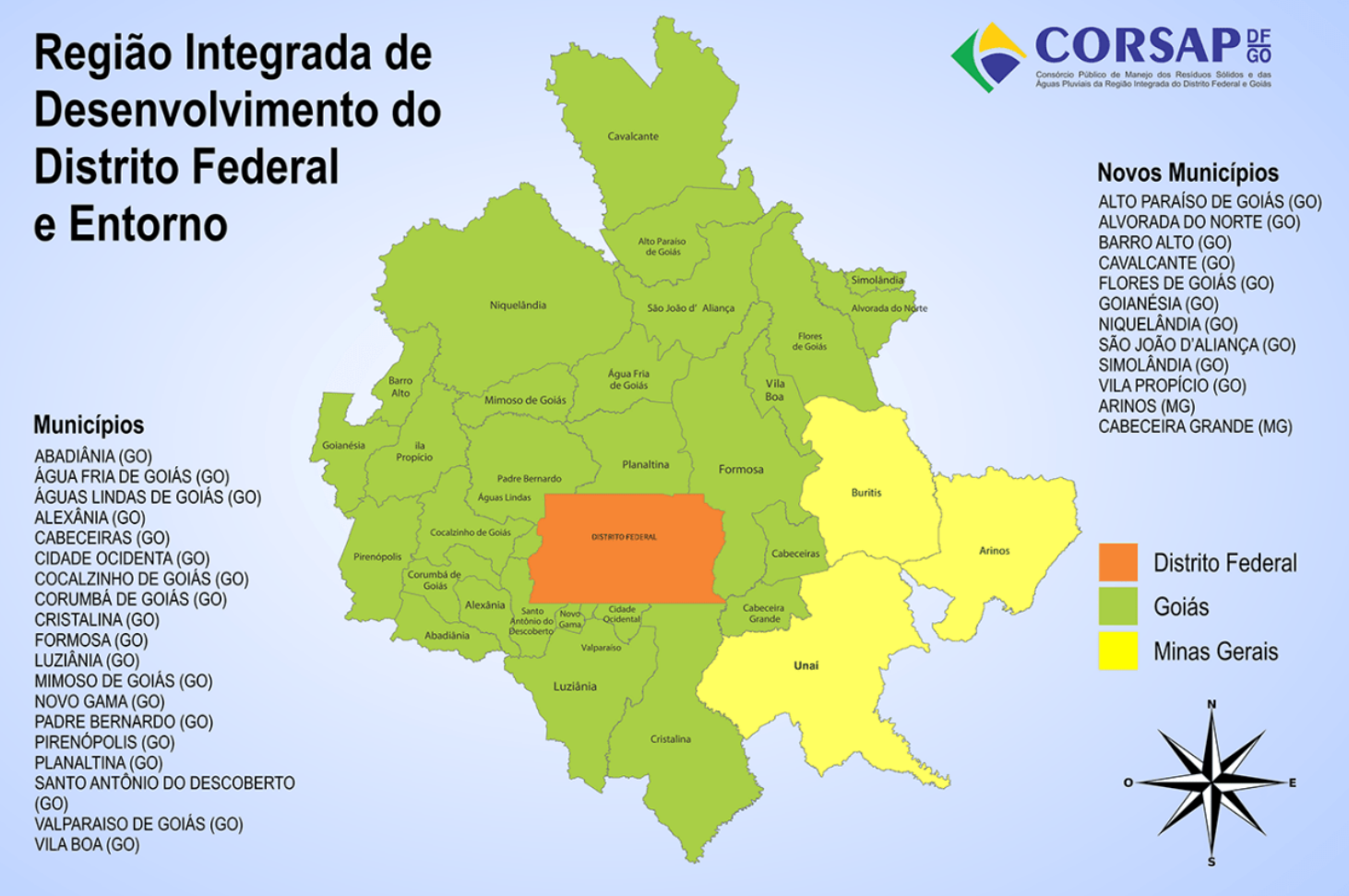

Fonte: CORSAP (2018).

Os burocratas de nível de rua e a seleção de casos de violência doméstica contra mulheres

Praticado um delito, surge para o Estado o poder-dever de punir, que depende de uma prévia persecução criminal para ser exercido. Ao prever a adoção de um sistema processual penal acusatório, caracterizado pela separação das funções de acusar, exercida precipuamente pelo Ministério Público, defender, exercida por meio de advogado, e julgar, exercida pelo Poder Judiciário, a Constituição Federal de 1988 buscou garantir a observância de direitos fundamentais, seja da vítima, seja do acusado. A investigação penal, exercida pela polícia judiciária, dirigida por Delegado de Polícia de carreira, a quem incumbe a adoção de diversos procedimentos policiais, é ponto de partida para uma persecução criminal bemsucedida e instrumento hábil a fortalecer o sistema acusatório, pois possibilita que o Poder Judiciário permaneça inerte (HOFFMANN et al., 2017). 
Incumbidas do exercício da função de polícia judiciária, às polícias civis compete investigar todos os crimes, que se submetem à ação penal pública incondicionada, que lhes são notificados, não podendo realizar juízo de conveniência e oportunidade, tendo em vista a incidência do princípio da obrigatoriedade da persecução penal nos referidos delitos. Como foi abordado, o crime de violência doméstica contra mulher submete-se à ação penal pública incondicionada, não sendo necessário, portanto, a autorização da vítima para que seja investigado e processado.

Dessa forma, ocorrido o crime de violência doméstica contra mulher, surgem duas possibilidades de atuação dos órgãos de segurança pública: a) surpreendido em situação de flagrante delito, o agressor deverá ser conduzido a uma Delegacia de Polícia para a lavratura do auto de prisão em flagrante, procedimento administrativo esse que se tornará peça inicial de um Inquérito Policial, no qual serão realizadas outras diligências necessárias antes de ser remetido ao Ministério Público e ao Poder Judiciário, contendo os elementos probatórios suficientes para embasar a denúncia; b) caso a situação fática apresentada não se enquadre em uma das hipóteses legais que ensejam a prisão em flagrante (agressor não encontrado pela Polícia Militar; vítima procura a Delegacia de Polícia e noticia o fato dias depois do ocorrido, etc.), o Delegado de Polícia deverá instaurar, mediante portaria, Inquérito Policial para a investigação do crime informado. De acordo com o artigo 10 do Código de Processo Penal, 0 Inquérito Policial deverá ser concluído no prazo de dez dias, se o indiciado tiver sido preso em flagrante, ou no prazo de 30 (trinta) dias, quando estiver solto. Considerando que a prisão em flagrante deve ser comunicada ao juiz no prazo de 24 (vinte e quatro) horas, inicia-se, por parte do órgão jurisdicional, a contagem do prazo legal de dez ou de trinta dias (BRASIL, 1941).

No entanto, não foram essas as situações observadas na pesquisa. Considerando que a subsunção do fato ao tipo penal da lesão corporal qualificada pela violência doméstica não permite inferir a direta aplicação dos preceitos da Lei $n . \stackrel{0}{11.340 / 2006}$, pois o sujeito passivo do referido crime pode ser do sexo feminino ou masculino, constatou-se que, do total de 2.226 (duas mil duzentas e vinte e seis) ocorrências de violência doméstica registradas no ano de 2019 nos vinte e nove municípios abrangidos, em 2.059 (duas mil e sessenta e sete) a vítima era mulher, e a relação interpessoal com o agressor se deu no âmbito doméstico e familiar ou foi íntima de afeto. Em 167 (cento e sessenta e sete) notificações, observou-se a não incidência da Lei Federal n. -11.340/2006, seja porque a vítima era do sexo masculino, seja porque vítima e agressora eram do sexo feminino.

Do total de notificações referentes ao delito de violência doméstica contra mulher praticada em ambiente doméstico ou familiar, em apenas 47,59\% (quarenta e sete inteiros e 
cinquenta e nove décimos por cento) foram instaurados Inquéritos Policiais, seja por meio de auto de prisão em flagrante, seja por meio de portaria do Delegado de Polícia responsável.

\section{Gráfico 1 - Quantidade de boletins de ocorrência que geraram inquérito policial}

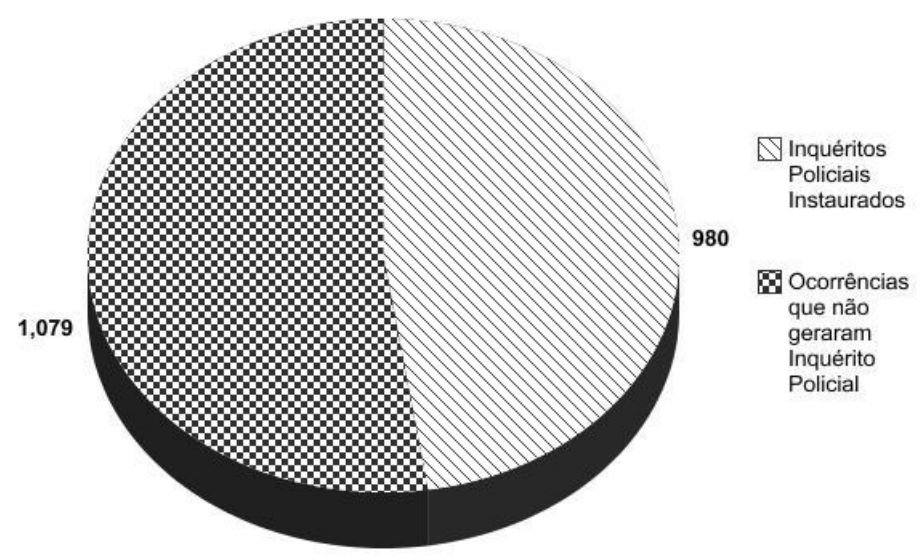

Fonte: Elaborado pelo autor (2020).

Do total de inquéritos policiais instaurados no período, 580 (quinhentos e oitenta) derivam de auto de prisão em flagrante, dos quais 88,62\% (oitenta e oito inteiros e sessenta e dois décimos por cento) foram remetidos ao Poder Judiciário e ao Ministério Público dentro do prazo legal de dez dias, previsto pelo Código de Processo Penal. Outrossim, 400 (quatrocentos) inquéritos policiais foram iniciados por meio de portaria do Delegado de Polícia, dos quais apenas 36\% (trinta e seis por cento) foram enviados ao Poder Judiciário, permanecendo, portanto, 64\% (sessenta e quatro por cento) dos procedimentos investigatórios instaurados de ofício sem o conhecimento dos órgãos responsáveis pela fase processual da persecução penal.

A grande diferença entre as porcentagens de remessa ao Poder Judiciário de inquéritos policiais instaurados por auto de prisão em flagrante e por portaria pode ser explicada pelo controle e fiscalização exercidos pelo Poder Judiciário. Ultrapassado o prazo estipulado pelo ordenamento jurídico, a autoridade policial responsável passa a ser cobrada pelo magistrado pela conclusão do inquérito ou pela sua remessa solicitando a dilação do prazo, uma vez que a autoridade judiciária tomou conhecimento dos fatos ao ser comunicada da prisão em flagrante. Quanto aos procedimentos instaurados por portaria, desde que não enviados ao Judiciário para a solicitação da dilação do prazo de investigação, como prevê o parágrafo 3ํㅡㄹ do artigo 10 , do Código de Processo Penal, não existe nenhuma fiscalização quanto ao cumprimento do prazo 
legal, seja por meio de controle interno exercido pela própria Polícia Civil, seja por meio do controle externo da atividade policial, exercido pelo Ministério Público e Poder Judiciário.

\section{Ocorrências que não geraram procedimentos policiais: A discricionariedade inerente ao trabalho policial como entrave à implementação de políticas públicas}

Das 2.059 (duas mil e cinquenta e nove) notícias de crime de violência doméstica contra mulher registradas entre janeiro e dezembro de 2019 nos vinte e nove municípios do Estado de Goiás que compõem a RIDE/DF, 52,40\% (cinquenta e dois inteiros e quarenta décimos por cento) não resultaram na instauração de procedimento investigatório. Nesses casos, a mulher vitimada em ambiente doméstico e familiar se vê, mesmo após o primeiro contato com os aparelhos públicos destinados a garantir-Ihe a segurança, seja a Polícia Militar, seja a Polícia Civil, entregue à própria sorte, tendo em mãos um papel de boletim de ocorrência capaz de, unicamente, torná-la estatística criminal.

Os referidos órgãos estaduais de segurança pública são responsáveis pelo exercício da função de policiamento, conceituado por Reiner (2004) como a tentativa de manter a segurança por meio de vigilância e ameaça de sanção. Ainda segundo o autor, todas as forças policiais, sejam as que exercem a função de patrulhamento uniformizado regular do espaço público, nos casos em análise, a Polícia Militar, sejam as que promovem a investigação após a ocorrência do crime ou desordem, para os objetivos da pesquisa, a Polícia Civil, têm se caracterizado por um poder discricionário exercido pelos níveis mais baixos de sua hierarquia organizacional, responsáveis diretos pela aplicação da lei e pela manutenção da ordem (REINER, 2004). Os motivos para essa discricionariedade seriam:

[...] um é que ela [a polícia] não tem, e nunca poderia ter, recursos adequados para a aplicação total de todas as leis. Existe, então uma necessidade inevitável de escolher entre prioridades. O segundo é que mesmo a regra legal mais explícita requer interpretações em situações concretas. Na prática, o caráter logicamente aberto das regras torna invevitável pelo menos um elemento implícito de poder discricionário. Tais considerações tornam o poder discricionário inevitável, mas ele também é desejável. $A$ aplicação da lei na sua totalidade iria violar critérios de justiça geralmente aceitos, como em casos em que, sem dúvida, a acusação não deve ocorrer, como aqueles envolvendo criminosos muito idosos ou muito jovens. (REINER, 2004, p. 242)

Ao analisar a atuação de policiais civis e militares na implementação da política de enfrentamento à violência contra mulheres no universo pesquisado, é possível acrescentar um terceiro motivo facilitador do exercício arbitrário da discricionariedade: a ausência de mecanismos confiáveis de monitoramento e controle, que permite aos agentes de linha agir em 
interesse próprio e, consequentemente, em detrimento dos interesses da sociedade, sem serem punidos por isso.

Como especificado por Lipsky (2010), os burocratas de nível de rua reconhecem a existência de regras que regem os procedimentos que deveriam ser adotados, bem como são inteirados pelas instituições acerca dos princípios que permeiam as políticas públicas que executam em sua atuação diária. No entanto, em razão dos motivos acima especificados, não conseguem, ou não desejam, adaptar as práticas exigidas à realidade por eles experimentadas. Tal realidade foi observada nos históricos dos boletins de ocorrência em situações em que, contrariando o disposto na Lei $\mathrm{n} . \stackrel{\circ}{1}$ 11.340/2006 acerca da natureza incondicionada da ação penal pública nos crimes de violência doméstica contra mulher, mesmo conduzidos para a Delegacia de Polícia vítima e agressor, mesmo existindo nos relatos dos policiais responsáveis pela ocorrência menção a lesões corporais ou vias de fato, os procedimentos policiais pertinentes não foram instaurados, sob a alegação de que a vítima não tinha interesse na persecução penal.

Ouvidos os envolvidos, não ficou evidenciado o dolo de lesionar por parte do autor em desfavor da vítima. Esta última não deseja dar continuidade a nenhum procedimento criminal e alega ter sido apenas uma confusão.

De acordo com o relato da Polícia Militar, a vítima não quis prosseguir com a ação, que declarou ao Delegado de Plantão (nome suprimido) que não acionou a Polícia Militar e não deseja dar continuidade com quaisquer procedimento (sic) contra seu companheiro.

Apresentados nesta Delegacia, todos os envolvidos relataram tratar-se de um mal entendido entre família e que não há de nenhuma das partes, especialmente de (nome suprimido), nenhum interesse em representar criminalmente, esclarecendo que não tem certeza se foi (nome do irmão da vítima suprimido) que the causou uma lesão no braço ou se foi seu próprio namorado, filho de (nome da genitora do namorado da vítima), que Ihe machucou tentando the segurar.

Observou-se ainda a existência de despachos nos boletins de ocorrência em que as autoridades policiais responsáveis pelo recebimento das ocorrências motivam a não ratificação da voz de prisão expedida pelos policiais militares. Os motivos alegados foram, principalmente, exercício de legítima defesa por parte do agressor; ausência de elementos probatórios robustos, em especial a ausência de testemunhas; e versões divergentes dos envolvidos acerca dos fatos.

Esta autoridade policial entrou em contato pelo telefone com (nomes dos genitores da vítima suprimidos), genitores de (Nome da vítima suprimido). Ambos enfatizaram que (Nome da vítima) e (nome do agressor) possuem um relacionamento conturbado. Afirmaram ainda que (nome da vítima), por diversas vezes, agride (Nome do agressor). (nome da genitora da vítima) disse que na data de hoje, (nome da vítima) jogou o capacete na direção de (nome do autor), bem como tentou agredi-lo. Informação que é corroborada pelo depoimento de (nome do autor). Diante dos fatos, entendo que (nome do autor) é a vítima e (nome da vítima) a suposta autora. 
Analisando os elementos de informação presentes, esta autoridade não identificou a autoria do evento, isto porque (nome do agressor) está bastante lesionado (vide relatório médica) enquanto que (nome da vítima) possui escoriações superficiais. Caso o intento de (nome do autor) fosse criminoso, provavelmente desferiria golpes de faca e/ou socos em face de (nome da vítima), bem como teria fugido do local do crime A ausência de testemunhas presenciais impede, neste momento, de análise diversa dos fatos, razão pela qual esta autoridade encerra o presente feito e a liberação das partes.

Entrevistadas as partes e comparando as versões apresentadas não é possível chegar a uma conclusão segura a favor do suposto autor ou da suposta vítima. $O$ autor nega qualquer agressão. A suposta vítima reconhece que pode ter acertado o autor durante a discussão, ainda que com o intuito defensivo. A única testemunha é a mãe do suposto autor, que desacreditou a versão da suposta vítima. Existem lesões em ambos os relatórios médicos. Assim, entende-se pela impossibilidade de se lavrar o APF, dada a fragilidade da materialidade das lesões, a impossibilidade de determinar a dinâmica na qual foram produzidas e dos parcos indícios de autoria.

Esta autoridade entrevistou as partes. Em síntese, a suposta vítima alega que após a discussão foi agredida fisicamente pelo autor. Este, por sua vez, nega a autoria e diz que somente desferiu um 'rodo' nas pernas da vítima porque ela o agrediu. Não houve testemunhas presenciais $O$ laudo pericial indica lesões em ambas as partes. Neste sentido, diante da autoria incerta e diante da incerteza de quem agiu em legítima defesa, esta autoridade encerra o presente e determina a liberação das partes.

Não existem vestígios de lesões, a não ser pequena marca próxima à boca da vítima. $O$ autor nega as agressões. Não foram apresentadas testemunhas do fato nesta Delegacia. Assim, entende-se pela impossibilidade de se lavrar o APF, dada a fragilidade da materialidade das lesões, a impossibilidade de determinar a dinâmica na qual foram produzidas e dos parcos indícios de autoria. Vítima e autor entraram em acordo da seguinte maneira: o autor se compromete a deixar o lar conjugal temporariamente. Pediu também desculpas à vítima. Sendo que a vítima aceitou as desculpas deste. Vítima dispensou medidas protetivas oferecidas. Autor se comprometeu a ir embora para o Riacho Fundo/DF, com sua mãe, ainda hoje.

Comparando as versões do conduzido e da suposta vítima, não é possível chegar a uma conclusão segura de quaisquer das versões apresentadas. Destaque-se que a suposta vítima está visivelmente embriagada. Esta também não foi capaz de narrar os fatos fazendo um encadeamento lógico.

É possível perceber nos históricos transcritos demonstrações de preconceito, machismo e discriminação daquele que deveria atuar, de acordo com a celebrada frase do Ministro Celso de Mello, como "primeiro garantidor da legalidade e da Justiça" (BRASIL, 2015, p. 48). Não se atribui a devida pertinência às palavras das mulheres vitimadas. Pelo contrário. Diante da ausência de testemunhas, característica comum a crimes praticados em ambiente doméstico ou familiar, ou da negação da violência por parte dos autores, os procedimentos policiais, seja o autor de prisão em flagrante, seja o Inquérito Policial, não são instaurados, e as mulheres, violentadas por aqueles com que mantém relação íntima e de afeto, veem os agressores colocados em liberdade, dando início a um novo ciclo de violência, desta feita com a anuência estatal. 


\section{CONCLUSÃO}

As políticas públicas adotadas pelo Governo brasileiro a partir de 2003 foram responsáveis por um grande avanço no enfrentamento à violência contra mulheres, tanto no quesito social, por meio do estímulo à atuação integrada entre os diversos organismos governamentais e não-governamentais de amparo à mulher, quanto na persecução criminal dos agressores, por meio da Lei $n .^{\circ} 11.340 / 2006$. A violência de gênero passou a ser debatida por toda a sociedade, trazendo luz a realidade antes circunscrita ao ambiente doméstico e, portanto, privada aos que nele se inseriam.

No entanto, como toda política pública disruptiva, que propõe o abandono das velhas estruturas organizacionais próprias do modelo tradicional de gestão, sua implementação encontra dificuldades, em especial em órgãos públicos tão fechados em si mesmos, como as polícias civil e militar. Quanto mais próxima a interação da burocracia com os receptores dos serviços públicos, quanto mais esparsos os objetivos e as metas estabelecidos pelos formuladores de políticas públicas e quanto mais difusos os processos de avaliação e fiscalização ou a total ausência deles, maior a discricionariedade atribuída aos burocratas de nível de rua, possibilitando, assim, a deturpação da ação estatal por valores, vontades e padrões comportamentais daqueles que efetivamente implementam o programa público.

A política de enfrentamento à violência contra mulheres apresenta todas essas características. A sua implementação se dá de forma precípua por policiais militares e civis, responsáveis que são pelos primeiros contatos das mulheres violentadas com o aparato estatal criado para protegê-las. Como se demonstrou, a ausência de um patamar mínimo de governança pública, em especial a falta de mecanismos de controle nos próprios órgãos analisados, e a ineficiência da fiscalização exercida pelos demais órgãos que compõem a justiça criminal, permitem um processo seletivo de casos que receberão a atuação estatal, permanecendo sem resposta mais de cinquenta e dois por cento das situações de violência doméstica contra mulheres analisadas na pesquisa. Outrossim, a falta de fiscalização faz com que a discricionariedade, que é inerente ao exercício da função de policiamento, extrapole os limites impostos pela política pública de enfrentamento à violência contra mulheres, gerando manifestações discriminatórias e preconceituosas que a própria política pública visa combater.

A mudança dessa cruel realidade passa por uma atuação firme de controle, avaliação e punição por parte dos órgãos internos e externos de controle da atividade policial, bem como pela adoção, por parte dos órgãos estaduais de segurança pública, de patamares mínimos de governança pública. 


\section{REFERÊNCIAS}

BRASIL. Decreto-Lei n. 3.689 , de 3 de outubro de 1941. Código de Processo Penal. Diário Oficial da União, Brasília, DF, 3 out. 1941. Disponível em: http://www.planalto.gov.br/ccivil_03/decreto-lei/del3689.htm. Acesso em: 23 nov. 2019.

BRASIL. Constituição (1988). Constituição da República Federativa do Brasil de 1988. Brasília, DF. Disponível em: http://www.planalto.gov.br/ccivil_03/constituicao/constituicao.htm. Acesso em: 24 nov. 2017.

BRASIL. Lei n 9.099, de 26 de setembro de 1995. Dispõe sobre os Juizados Especiais Cíveis e Criminais e dá outras providências. Diário Oficial da União, Brasília, DF, 26 set. 1995. Disponível em: http://www.planalto.gov.br/ccivil_03/LEIS/L9099.htm. Acesso em: 20 nov. 2019.

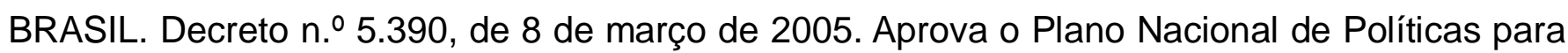
as Mulheres - PNPM, institui o Comitê de Articulação e Monitoramento e dá outras providências. Diário Oficial da União, Brasília, DF, 8 mar. 2005. Disponível em: http://www.planalto.gov.br/ccivil_03/_Ato2004-2006/2005/Decreto/D5390.htm. Acesso em: 22 nov. 2019.

BRASIL. Lei $\mathrm{n}^{\circ} \mathbf{1 1 . 3 4 0}$, de 7 de agosto de 2006. Cria mecanismos para coibir a violência doméstica e familiar contra a mulher, nos termos do $\S 8^{\circ}$ do art. 226 da Constituição Federal.

Diário Oficial da União, Brasília, DF, 7 ago. 2006. Disponível em: http://www.planalto.gov.br/ccivil_03/_ato2004-2006/2006/lei/l11340.htm. Acesso em: 17 nov. 2019.

BRASIL. Secretaria Especial de Políticas para as Mulheres. Plano Nacional de Políticas para as Mulheres. 2008. Disponível

em:

http://portal.mec.gov.br/dmdocuments/planonacional_politicamulheres.pdf. Acesso em: 13 nov. 2019.

BRASIL. Secretaria de Políticas para as Mulheres. Pacto Nacional pelo Enfrentamento à Violência contra as Mulheres. 2011. Disponível em: https://www12.senado.leg.br/institucional/omv/entenda-a-violencia/pdfs/pacto-nacional-peloenfrentamento-a-violencia-contra-as-mulheres. Acesso em: 11 nov. 2019.

BRASIL. Supremo Tribunal de Justiça. Habeas Corpus n. 84.548. São Paulo. Relator: Ministro Marco Aurélio Mello. Tribunal Pleno, Brasília, DF, 04 mar. 2015. Disponível em: http://redir.stf.jus.br/paginadorpub/paginador.jsp?docTP=AC\&docID=630134. Acesso em: 25 nov. 2019.

BRASIL. Decreto n. 9.203, de 22 de novembro de 2017. Dispõe sobre a política de Governança da administração pública federal direta, autárquica e fundacional. Diário Oficial da União, Brasília, 2017. Disponível em: http://www.planalto.gov.br/ccivil_03/_ato20152018/2017/decreto/D9203.htm. Acesso em: 15 fev. 2020.

BRASIL. Presidência da República. Guia da Política de Governança Pública. 2018. Disponível em: https://www.defesa.gov.br/arquivos/pdf/governanca/guia-da-politica-degovernanca-publica.pdf. Acesso em: 15 fev. 2020. 
BIROLI, Flávia. Gênero e Desigualdades: limites da democracia no Brasil. São Paulo: Boitempo, 2018.

BRONZO, Carla; COSTA, Bruno Lazzarotti Diniz. Intersetorialidade no enfrentamento da pobreza: o papel da implementação e da gestão. In: FARIA, Carlos Aurélio Pimenta de. (Org.). Implementação de políticas públicas: teoria e prática. Belo Horizonte: PUC Minas, 2012.

CALAZANS, Myllena; CORTES, láris. O processo de criação, aprovação e implementação da Lei Maria da Penha. In: CAMPOS, Carmem Hein de. (Org.). Lei Maria da Penha comentada em uma perspectiva jurídico-feminista. Rio de Janeiro: Lumen Juris, 2011.

CAPELLA, Ana Cláudia Niedhardt. Perspectivas teóricas sobre o processo de formulação de políticas públicas. Revista Brasileira de Informações Bibliográficas em Ciências Sociais BIB, n. 61, 1 sem. 2006. Disponível em: http://www.anpocs.org/index.php/edicoesanteriores/bib-61. Acesso em: 10 nov. 2019.

CERQUEIRA, Daniel et al. Avaliando a efetividade da Lei Maria da Penha. 2015. Disponível em: https://www12.senado.leg.br/institucional/omv/entenda-a-violencia/pdfs/a-efetividade-dalei-maria-da-penha. Acesso em: 18 nov. 2019.

CONSÓRCIO PÚBLICO DE MANEJO DOS RESÍDUOS SÓLIDOS E DAS ÁGUAS FLUVIAIS DA REGIÃO INTEGRADA DO DISTRITO FEDERAL E GOIÁS - CORSAP DF/GO. Região Integrada de Desenvolvimento do Distrito Federal e Entorno. 2018. Disponível em: https://corsapdfgo.eco.br/. Acesso em: 30 nov. 2019.

FARAH, Marta Ferreira Santos. Abordagens teóricas no campo de política pública no Brasil e no exterior: do fato à complexidade. Rev. Serv. Público, v. 69, p. 53-84, dez. 2018.

FÓRUM BRASILEIRO DE SEGURANÇA PÚBLICA - FBSP. 13 Anuário Brasileiro de Segurança Pública. 2019. Disponível em: http://www.forumseguranca.org.br/publicacoes/13anuario-brasileiro-de-seguranca-publica. Acesso em: 12 set. 2019.

HOFFMANN, Henrique et al. Investigação Criminal pela Polícia Judiciária. 2. ed. Rio de Janeiro: Lumen Juris, 2017.

INSTITUTO DE PESQUISA ECONÔMICA E APLICADA - IPEA. Infraestrutura Social e Urbana no Brasil: subsídios para uma agenda de pesquisa e formulação de políticas públicas. Brasília: $\quad$ IPEA, 2010. Disponível em: http://www.ipea.gov.br/portal/images/stories/PDFs/livros/livros/42543_Livro_InfraestruturaSocial _vol2.pdf. Acesso em: 18 set. 2019.

JENSEN, Michael; MECKLING, William. Theory of the firm: Managerial behavior, agency costs and ownership $\quad$ structure. $1976 . \quad$ Disponível em: https://www.sciencedirect.com/science/article/pii/0304405X7690026X. Acesso em: 15 jan. 2020.

LIPSKY, Michael. Street-level Bureaucracy: dilemmas of the individual in public services. New York: Russel Sage Foundation, 2010.

LOTTA, Gabriela Spanghero. O papel das burocracias do nível de rua na implementação de políticas públicas: entre o controle e a discricionariedade. In: FARIA, Carlos Aurélio Pimenta de. (Org.). Implementação de políticas públicas: teoria e prática. Belo Horizonte: PUC Minas, 2012. 
MARQUES, Maria da Conceição da Costa. Aplicação dos princípios da governança corporativa ao sector público. RAC, v. 11, n. 2, p. 11-26, abr./ jun. 2007.

PEREZ, José Roberto Rus. Avaliação do processo de implementação: algumas questões metodológicas. In: RICO, Elizabeth Melo (Org.). Avaliação de políticas sociais: uma questão em debate. 5. ed. São Paulo: Cortez, 2007.

PRZEWORSKI, Adam. Sobre o desenho do Estado: uma perspectiva agente x principal. In: BRESSER PEREIRA, Luiz Carlos; SPINK, Peter (Orgs.). Reforma do Estado e administração pública gerencial. Rio de Janeiro: Editora da FGV, 1998.

REINER, Robert. A Política da Polícia. São Paulo: Editora da Universidade de São Paulo, 2004.

SANTOS, Cecília MacDowell. Da delegacia da mulher à Lei Maria da Penha: absorção/tradução de demandas feministas pelo Estado. Revista Crítica de Ciências Sociais, v. 89, p. 153-170, 2010. Disponível em: https://journals.openedition.org/rccs/3759. Acesso em: 20 ago. 2019.

SECCHI, Leonardo. Políticas Públicas: conceitos, esquemas de análise, casos práticos. São Paulo: Cengage Learning, 2017. 